\title{
An analysis of six patients with Parkinson's disease who have been unresponsive to L-dopa therapy
}

\author{
ROBERT J. MONES
}

From the Mt. Sinai School of Medicine, New York, New York, U.S.A.

SUMMARY Six patients diagnosed as Parkinson's disease on a clinical basis alone are described, and their response to L-dopa and to alpha methyl dopa hydrazine (MK 486) and L-dopa. They are compared with 239 other patients with Parkinson's disease treated in the same time period. These six patients were unusual in that they did not have a clinical response to L-dopa, nor did they develop dyskinesias on L-dopa or on L-dopa with MK 486, although they showed high blood levels of L-dopa and high homovanillic acid levels in the spinal fluid. Unresponsiveness to L-dopa is attributed to a specific brain mechanism and not to problems of transport of L-dopa to the brain or to abnormal peripheral metabolism of L-dopa. The term 'motor unresponsiveness to L-dopa' may be useful to describe such patients who may eventually be shown to be suffering from diseases other than Parkinsonism.

The use of L-dopa in patients with Parkinson's disease was started in a clinically useful manner by Cotzias, Van Woert, and Schiffer (1967). Numerous articles since that time have confirmed this initial report that L-dopa is the treatment of choice for Parkinson's disease (Barbeau, 1969; Cotzias, Papavasiliou, and Gellene, 1969; Yahr, Duvoisin, Schear, Barrett, and Hoehn, 1969; McDowell, Lee, and Swift, 1970; Mones, Elizan, and Siegel, 1970). This paper is an analysis of six patients with Parkinson's disease who did not have a clinical response to L-dopa, nor did they develop dyskinesias to the drug or to a combination of L-dopa and alpha methyl dopa hydrazine (MK 486, a dopa decarboxylase inhibitor). These patients have been considered to have 'motor unresponsiveness to L-dopa'. They will be compared with 239 other patients with Parkinson's disease who have been treated with L-dopa and/or L-dopa-MK 486 combination during the same time period and in the same institution.

\section{METHODS}

Two hundred and forty-five patients with Parkinson's disease were started on L-dopa therapy from November 1968 to June 1969 at the Mount Sinai Medical
Center. They were seen by at least two neurologist who believed from a purely clinical standpoint tha the patients had Parkinson's disease. The first 150 patients were treated with L-dopa as inpatients, and the last 95 patients were treated exclusively as out patients. The details of their treatment course methods of rating, and follow-ups have been pub lished previously (Mones et al., 1970). All of these patients were given a trial of anticholinergic drugs or amantadine if they did not respond successfully to L-dopa alone.

Table 1 summarizes the results of these 245 patients on 1 January 1972. The side-effects of L-dopa therapy listed represent the significant difficulty with L-dopa which limited the efficacy of the drug in

TABLE 1

245 PARKINSON'S DISEASE PATIENTS STARTED ON L-DOPA NOVEMBER 1968-JUNE 1969: STATUS ON 1 JANUARY 1972

\begin{tabular}{lccccc}
\hline $\begin{array}{c}\text { Limiting } \\
\text { side-effect of } \\
\text { L-dopa }\end{array}$ & $\begin{array}{c}\text { Doing } \\
\text { well }\end{array}$ & $\begin{array}{c}\text { Improved } \\
\text { but recent } \\
\text { progression }\end{array}$ & $\begin{array}{c}\text { Responded } \\
\text { but now } \\
\text { worse }\end{array}$ & $\begin{array}{c}\text { Never } \\
\text { responded }\end{array}$ & $\begin{array}{c}\text { Died or } \\
\text { off drug }\end{array}$ \\
\hline Dyskinesia & $(89)$ & $(34)$ & $(26)$ & $(32)$ & $(64)$ \\
Nausea & 49 & 18 & 9 & 6 & \\
Mental changes & 19 & 8 & 7 & 12 & \\
Dizziness & 4 & 5 & 4 & 2 & \\
& 1 & 1 & 1 & 2 & \\
\hline
\end{tabular}

Total numbers of patients in parentheses. 
these patients. Minor problems such as temporary nausea, vomiting, or dizziness which disappeared in subsequent weeks are not listed, as this type of toxicity did not limit the efficacy of the drug.

A second study relating to the same patients was started in November 1970 using alpha methyl dopa hydrazine (MK 486) in combination with L-dopa. Twenty patients of the 245 in Table 1 were selected for trial of MK 486. Eleven were selected because their poor response to L-dopa appeared to be related to nausea, and vomiting caused by L-dopa. Most of these patients had a definite improvement in their clinical status with the addition of MK 486. Two other patients whose major problem with L-dopa was induced dyskinesias were studied and one patient who had psychic disturbances from L-dopa was given a trial of MK 486. These patients will be reported in detail in another paper.

Six patients were selected from the 245 because of their lack of response to L-dopa therapy. They were admitted to the Clinical Research Center of the Mount Sinai Hospital, New York City, and a double blind evaluation of MK 486 was done in combination with L-dopa. These patients had all been on L-dopa for at least one year and were taking their maximal allowable amount, which ranged between 4 and $7 \mathrm{~g}$ per day. Placebo was then substituted for L-dopa and the patients were observed in the hospital off L-dopa for three or four days. Base line studies of their neurological and medical status were done and cinematic recordings were made. Two hundred milli- grams per day of MK 486 was added, unknown to the patients, and then the L-dopa was gradually raised by $250 \mathrm{mg}$ per day in a 'blind' fashion until the patients were receiving their maximal, allowable L-dopa dosage or until they developed toxicity from the combination of drugs which made it impossible to continue the trial. During hospitalization, these patients had frequent determinations of L-dopa blood level two hours after the morning or afternoon dosage. Spinal fluid homovanillic acid levels were determined when the patient was on L-dopa alone and later, when the patient was on MK 486 and maximal L-dopa therapy. Daily neurological examinations were performed and weekly movie recordings were made. These cases are summarized in Table 2.

\section{DISCUSSION}

A number of possible causes for treatment failures with L-dopa therapy in patients with basal ganglia disease are as follows:

1. The patients may have a brain disease other than Parkinsonism. When such patients do not have a clinical response to L-dopa and do not develop induced dyskinesias to the drug, one might consider them to have 'motor unresponsiveness to L-dopa'.

2. The side-effects of L-dopa such as nausea, vomiting, hypotension, and mental changes may

TABLE 2

CLINICAL DETAILS OF SIX PATIENTS

\begin{tabular}{|c|c|c|c|c|c|c|c|c|c|c|c|c|}
\hline \multicolumn{3}{|c|}{ Patient } & \multirow{2}{*}{\multicolumn{4}{|c|}{$\begin{array}{l}\text { Disease symptoms } \\
(0-4) \text { rating }\end{array}$}} & \multicolumn{2}{|c|}{ Maximum dosage } & \multirow{2}{*}{\multicolumn{2}{|c|}{$\begin{array}{c}\text { Response } \\
(0-4) \text { Rating }\end{array}$}} & \multicolumn{2}{|c|}{ Biochemistry } \\
\hline \multirow{2}{*}{ No. } & \multirow{2}{*}{$\begin{array}{l}\text { Age } \\
(y r)\end{array}$} & \multirow{2}{*}{$\begin{array}{c}\text { Years with } \\
\text { Parkinsonism }\end{array}$} & & & & & $L-d o p a$ & $M K 486$ & & & Highest & Highest \\
\hline & & & Tremor & Rigidity & Gait & Akinesia & (g/day) & $\begin{array}{c}(200 \mathrm{mg} / \text { day }) \\
\text { L-dopa } \\
(\mathrm{g} / \text { day })\end{array}$ & $\begin{array}{l}\text { Clinical } \\
\text { improve- } \\
\text { ment }\end{array}$ & Dyskinesia & $\begin{array}{l}\text { blood } \\
\text { L-dopa level } \\
\text { (mcg/ml.) }\end{array}$ & $\begin{array}{c}C S F H V A \\
\text { level } \\
(n g / m l .)\end{array}$ \\
\hline 1 & 71 & 11 & $\frac{1}{2}$ & 2 & 3 & 3 & 6 & $3 \cdot 7$ & 0 & 0 & $4 \cdot 4$ & 168 \\
\hline 2 & 73 & 2 & $\begin{array}{l}2 \\
\frac{1}{2}\end{array}$ & 2 & 3 & 2 & 6 & $2 \cdot 5$ & 0 & 0 & 0.67 & 122 \\
\hline 3 & 43 & 2 & $0^{2}$ & 1 & 1 & 2 & 6 & $3 \cdot 5$ & 0 & 0 & $8 \cdot 7$ & 238 \\
\hline 4 & 68 & 3 & 0 & 2 & 3 & 3 & 5 & $3 \cdot 5$ & 0 & 0 & $1 \cdot 1$ & 182 \\
\hline 5 & 73 & 6 & 0 & 2 & 3 & 3 & 6 & $3 \cdot 7$ & 0 & 0 & $1 \cdot 19$ & 73 \\
\hline 6 & 70 & 9 & 0 & 2 & 3 & 2 & 6 & $3 \cdot 7$ & 0 & 0 & 2.68 & 400 \\
\hline
\end{tabular}

Table 2 summarizes the clinical aspects of six patients cited in this paper. All six patients were treated with L-dopa before being given a combination of L-dopa and MK 486, a dopa decarboxylase inhibitor (see text). The characteristics of the Parkinson's disease is shown in the Disease svmptoms heading. Note that tremor occurred only minimally in the first two patients, whereas it was completely absent in the last four. Gait disturbance and akinesia were prominent in all six cases.

The Maximum dosage heading indicates the maximum amount of $\mathrm{L}$-dopa taken during the trial of that drug alone. The second trial of drugs included $200 \mathrm{mg} \mathrm{MK} \mathrm{486/day} \mathrm{with} \mathrm{L-dopa.} \mathrm{Note} \mathrm{that} \mathrm{these} \mathrm{six} \mathrm{patients} \mathrm{showed} \mathrm{no} \mathrm{response} \mathrm{to} \mathrm{L-dopa} \mathrm{or} \mathrm{to} \mathrm{the} \mathrm{combination} \mathrm{of} \mathrm{L-dopa} \mathrm{and}$ MK 486. The Biochemistry figures reveal the highest L-dopa blood levels during the patients' hospitalization period when on maximal amount of L-dopa plus MK 486. The L-dopa blood levels were drawn two hours after the morning MK 486 and L-dopa oral dose. The spinal fluids were tested at numerous intervals during the hospitalization, and the highest homovanillic acid level is shown in ng/ml.

The normal L-dopa blood level in patients not receiving L-dopa is 0 . The normal homovanillic acid level in the spinal fluid is less than $50 \mathrm{ng}$ $/ \mathrm{ml}$. Thus, in all six patients, an elevation of L-dopa blood level and spinal fluid homovanillic acid level was noted, even though the patients showed no clinical response to the drug. 
limit the amount of L-dopa taken, and in this way limit the efficacy of the drug.

3. Some patients may have the inability to transport L-dopa to the brain because of poor absorption in the gut, or because of increased peripheral decarboxylation or deamination of L-dopa.

4. A lack of the decarboxylation enzyme in the striatum may reduce the formation of dopamine from L-dopa.

The diagnosis of Parkinson's disease represents a problem to clinicians because other diseases have features of Parkinson's disease. An objective biochemical or clinical test is a most pressing need because of recent developments in L-dopa therapy. The definition of Parkinson's disease as a syndrome of dopamine deficiency in the striatum is of interest; however, it is of little help to the clinician who must diagnose and treat patients. Studies of the spinal fluid homovanillic acid concentration have not yet established criteria for defining Parkinson's disease (Moir, Ashcroft, Crawford, Eccleston, and Guldberg, 1970). The following diseases may mimic Parkinsonism and create diagnostic problems:

PROGRESSIVE SUPRANUCLEAR BULBAR PALSY, OR THE STEELE-RICHARDSON-OLSZEWSKI SYNDROME (Steele, Richardson, and Olszewski, 1960) These patients have abnormal eye movements, dementia, and bulbar findings in addition to akinesia and rigidity. Many cases of Parkinson's disease have some of these features and it is therefore difficult to differentiate this syndrome from other forms of Parkinsonism. Tremor, however, is not present in this syndrome.

THE SHY-DRAGER SYNDROME (Shy and Drager, 1960; Thomas and Schirger, 1963) Patients with this entity have evidence of decreased sympathetic tone revealing low blood pressure, decreased sweating, incontinence, and sexual impotence. They also have basal ganglia disturbances manifest by rigidity and akinesia. Tremor is not prominent.

STRIATAL-NIGRAL DEGENERATION (Adams and Van Bogaert, 1964; Andrews, Terry, and Spataro, 1970) This rare disease has been described only from pathological material in a total of 19 patients in the literature. Most of the patients described in these papers have the clinical diagnosis of Parkinson's disease made in life. Andrews et al. studied five cases of striatalnigral degeneration diagnosed pathologically. They could not distinguish the clinical picture from that of Parkinson's disease, although there was a lack of tremor as a prominent symptom. Andrews et al. predicted that these patients would not respond to L-dopa because of the severe striatal degeneration they found.

LOW PRESSURE HYDROCEPHALUS (Hakim and Adams, 1965) This is an entity which has been diagnosed more recently because of a greater use of radioisotopes and RISA intrathecal studies. Such patients have gait disturbance, akinesia, and organic mental syndrome. Tremor is not found but many such patients resemble cases of Parkinson's disease.

Three other conditions with basal ganglia disturbances and occasional akinesia and rigidity usually do not create diagnostic problems be cause of their other clinical manifestationso These diseases are Jakob-Creutzfeld disease Parkinson dementia syndrome of Guam (Hiranoo Kurland, Krooth, and Lessel, 1961), and olivo= pontocerebellar degeneration (Klawans and Zeitlin, 1971).

In any study of Parkinson's disease, one must understand the difficulty of diagnosing it and of categorizing patients. Parkinson's disease is probably a syndrome in which various entities are lumped together. In trials of L-dopa in Parkinson's disease groups, many authors have noted a lack of response between 5 and 20 per cent of these patients studied. Various explanations have been given to explain these therapeutic failures.

Yahr (1970) and Gerstenbrand (1970) mention the possibility that a lack of dopa decarboxylase in the striatum could be responsible for treatment failures. Birkmayer (1970) noted in two patients that complete lack of pigmentation in the substantia nigra was correlated with the lack of response, whereas the one patient with partial pigmentation of the substantia nigra did respond to L-dopa. The inference in these studies is that 
patients with end-stage Parkinson's disease may not respond to L-dopa because of permanent pathological changes in the nigral-striatal system. Lieberman, Goodgold, and Goldstein (1972) also noted that patients at this stage did not improve with L-dopa even though they handled C-14 L-dopa in a manner similar to responding patients. There are, however, a number of bedridden patients with Parkinson's disease who do respond to L-dopa, so that these explanations are not complete. Markham (1970) and Yahr (1970) also have regarded some of the patients who did not respond to L-dopa as possibly being misdiagnosed.

In our total series of 245 patients, 27 patients were clinically unresponsive to L-dopa. Nineteen of these had no induced dyskinesias and thus were considered to have 'motor unresponsiveness to L-dopa'. The six patients studied in this paper were from this group of 19. The L-dopa blood levels during this course of L-dopa-MK 486 therapy were high in all six patients and this implies that the transportation of L-dopa from the gut to the blood and, subsequently, to the brain was not the critical problem to explain an unresponsive state. The elevation of homovanillic acid in the spinal fluid supports this thesis, although this is not complete evidence of a turn-over of L-dopa to dopamine in the neurones of the striatum (Bartholini, Tissot, and Pletscher, 1971).

The lack of induced dyskinesias in the nonresponding patients is of interest as all other 14 patients who had a trial of MK 486 and L-dopa developed dyskinesias during their hospital stay although their blood levels and the spinal fluid homovanillic acid levels were comparable with the other six patients (Figure).

The clinical evaluation of these six unresponsive patients reveals that akinesia and rigidity was the prominent feature of all six, whereas tremor was present in only a mild form in two patients and absent in four. In this important respect these patients are similar to those with diseases which mimic Parkinsonism which have been discussed above.

An important pathological study of the brains of 26 patients diagnosed in life as having Parkinson's disease was reported by Stadlan, Duvoisin, and Yahr (1966). In this paper, 21 patients were considered to have classical Parkinson's disease with rigidity, tremor, and akinesia. Nineteen of these 21 had Lewy bodies in the substantia nigra. The two patients who did

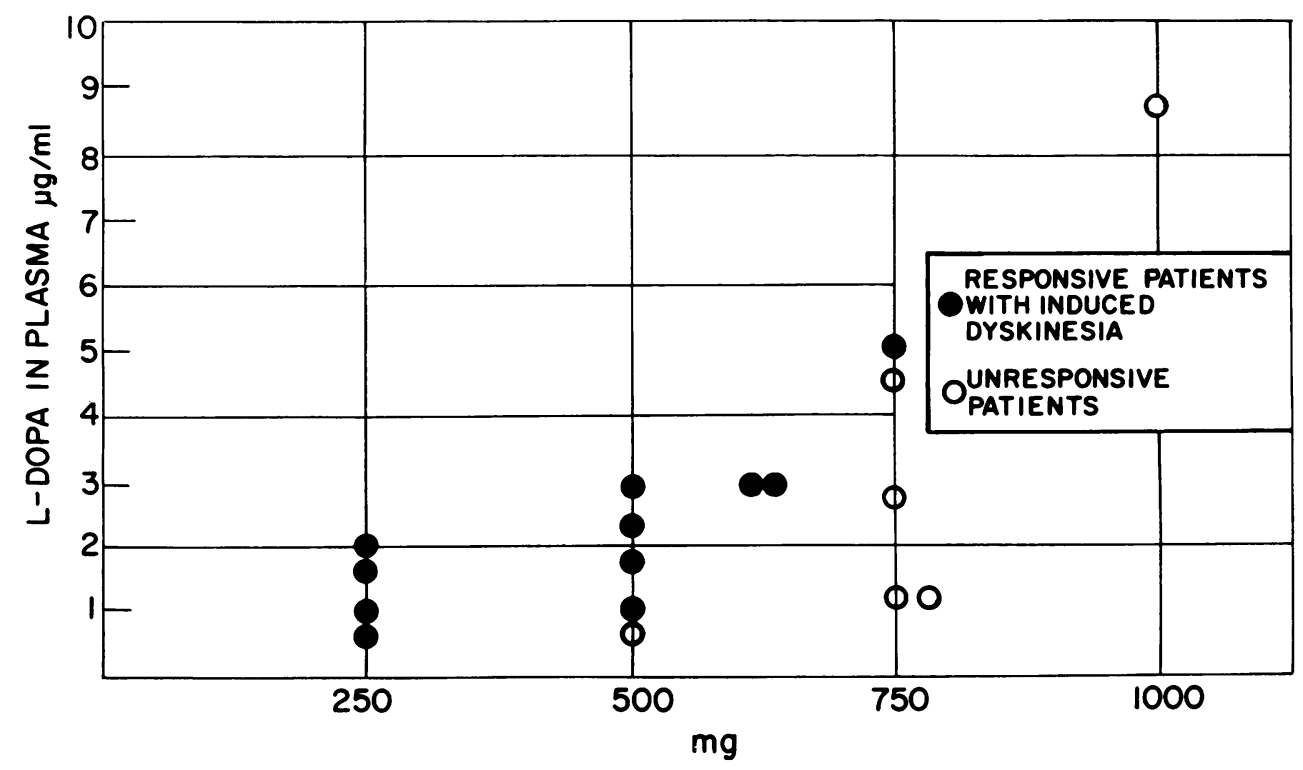

FIGURE. Oral dose of L-dopa two hours before blood sample. MK $48650 \mathrm{mg}$ given with L-dopa. 
not have this finding both had Parkinson's disease which started in their early 30 s, which in itself is atypical and makes a clinician consider the possibility of post-encephalitic Parkinsonism. One other patient with a clear post-encephalitic history did not have Lewy bodies in the substantia nigra. The four patients who were considered to have atypical Parkinson's disease in life because of the lack of tremor and the prominence of akinesia did not have Lewy bodies in the substantia nigra and, therefore, were considered by these authors possibly to represent some entity other than Parkinson's disease. This type of pathological information would support our findings that patients without tremor who do not respond to L-dopa may represent some other diagnostic category. Unfortunately, we do not yet have any pathological material in these nonresponding cases to prove this hypothesis. It is of interest in this regard that the production of L-dopa induced dyskinesias in patients who do not have Parkinsonism is rare. In our own experience, we have not seen dyskinesias occur in patients with multiple sclerosis, dystonia, and psychogenic disorders. The production of induced dyskinesias has been reported, however, by Barbeau (1969) in patients with Huntington's chorea, and by Lieberman et al. (1972) in one patient with amyotrophic lateral sclerosis. The production of dyskinesias in patients with Parkinson's disease is usually concomitant with the improvement of the clinical status of the patients (Mones, Elizan, and Siegel, 1971).

Side-effects of L-dopa such as nausea, vomiting, decreased blood pressure, and mental changes can limit the efficacy of the drug and are responsible for therapeutic failures. The lack of a clinical response and of induced dyskinesias in patients who have high blood levels of L-dopa may indicate that these side-effects are not the limiting factor in the L-dopa trial.

Inability to transport L-dopa from the blood to the brain may be a problem. The six patients of this report all had increased L-dopa blood levels and increased HVA levels in the spinal fluid. This would indicate that the transport of L-dopa to the brain was not the cause of the non-responding state.

A reduction of decarboxylation of L-dopa in the brain to dopamine could possibly explain treatment failures. The increased homovanillic acid (HVA) in the spinal fluid is indirect evidence that there is a turn-over of L-dopa to dopamine to HVA in the brain; however, pathological studies are needed in patients who have been treated with L-dopa.

These six patients may represent some other disease entity separate from Parkinson's disease. Striatal-nigral degeneration is a possible category, although no pathological proof is available and there is no information in the literature concerning the response of patients with striatalnigral degeneration to L-dopa. The lack of response to L-dopa and the absence of induced dyskinesias which we have called 'motor unresponsiveness to L-dopa' may be a useful term in describing these patients. Pathological and biochemical studies on the brains of patients with Parkinson's disease treated with L-dopa are needed to clarify the diagnostic and therapeutic problems that have been cited in this paper.

MK 486 (alpha methyl dopa hydrazine) was sup plied by Merck, Sharpe and Dohme Laboratories, West Point, Pa. The plasma L-dopa determination were done by the Merck Institute for Therapeutio Research, West Point, Pa., under the direction of George O. Breault, PhD. The Clinical Research Center of the Mount Sinai Hospital is funded bo NIH Grant RR-71.

\section{REFERENCES}

Adams, R. D., Bogaert, L. van, and Eecken, H. van der (1964). Striato-nigral degeneration. Journal of Neuropathology and Experimental Neurology, 23, 584-608.

Andrews, J. M., Terry, R. D., and Spataro, J. (1970). Striatonigral degeneration. Archives of Neurology, 23, 319-329.

Barbeau, A. (1969). L-dopa therapy in Parkinson's disease. Canadian Medical Association Journal, 101, 791-800.

Bartholini, G., Tissot, R., and Pletscher, A. (1971). Brain capillaries as a source of homovanillic acid in cerebrospinal fluid. Brain Research, 27, 163-168.

Birkmayer, W. (1970). Failures in L-dopa therapy. In L-Dopa and Parkinsonism, pp. 12-16. Edited by A. Barbeau and F. H. McDowell. Davis: Philadelphia.

Cotzias, G. C., Van Woert, M. H., and Schiffer, L. M. (1967). Aromatic amino acids and modification of Parkinsonism. New England Journal of Medicine, 276, 374-379.

Cotzias, G. C., Papavasiliou, P. S., and Gellene, R. (1969). Modification of Parkinsonism: chronic treatment with L-dopa. New England Journal of Medicine, 280, 337-345.

Gerstenbrand, F. (1970). Failures of L-dopa treatment. In L-Dopa and Parkinsonism, pp. 16-20. Edited by A. Barbeau and F. H. McDowell. Davis: Philadelphia.

Hakim, S., and Adams, R. D. (1965). The special clinical $N$ problem of symptomatic hydrocephalus with normal cerebrospinal fiuid pressure. Journal of Neurological Sciences, 2, 307-327.

Hirano, A., Kurland, L. T., Krooth, R. S., and Lessell, S. 
(1961). Parkinson-dementia complex, an endemic disease on the island of Guam: 1. Clinical features. Brain, 84, 642661.

Klawans, H. L., Jr., and Zeitlin, E. (1971). L-dopa in Parkinsonism associated with cerebellar dysfunction (probably olivopontocerebellar degeneration). Journal of Neurology, Neurosurgery, and Psychiatry, 34, 14-19.

Lieberman, A. N., Goodgold, A. L., and Goldstein, M. (1972). Treatment failures with levodopa in parkinsonism. Neurology (Minneap.), 22, 1205-1210.

McDowell, F. H., Lee, J. E., Swift, T., Sweet, R. D., Ogsbury, J. S., and Kessler, J. T. (1970). Treatment of Parkinson's syndrome with L-dihydroxyphenylalanine (levodopa). Annals of Internal Medicine, 72, 29-35.

Markham, C. H. (1970). Major treatment problems in L-Dopa therapy in Parkinson's disease. L-Dopa and Parkinsonism, pp. 10-12. Edited by A. Barbeau and F. H. McDowell. Davis: Philadelphia.

Moir, A. T. B., Ashcroft, G. W., Crawford, T. B. B., Eccleston, D., and Guldberg, H. C. (1970). Cerebra metabolites in cerebrospinal fluid as a biochemical approach to the brain. Brain, 93, 357-368.

Mones, R. J., Elizan, T. S., and Siegel, G. J. (1970). Evaluation of L-dopa therapy in Parkinson's disease. New York State Journal of Medicine, 70, 2309-2318.
Mones, R. J., Elizan, T. S., and Siegel, G. J. (1971). Analysis of L-dopa induced dyskinesias in 51 patients with Parkinsonism. Journal of Neurology, Neurosurgery, and Psychiatry, 34, 668-673.

Shy, G. M., and Drager, G. A. (1960). A neurological syndrome associated with orthostatic hypotension. Archives of Neurology, 2, 511-527.

Stadlan, E. M., Duvoisin, R., and Yahr, M. (1966). The pathology of Parkinsonism. In Proceedings of the Fifth International Congress of Neuropathology, Zürich 1965, pp. 569-571. Edited by F. Lüthy and A. Bischoff. International Congress Series No. 100. Excerpta Medica: Amsterdam.

Steele, J. C., Richardson, J. C., and Olszewski, J. (1964). Progressive supranuclear palsy. Archives of Neurology and Psychiatry, 10, 333-359.

Thomas, J. E., and Schirger, A. (1963). Neurologic manifestations in idiopathic orthostatic hypotension. Archives of Neurology, 8, 204-208.

Yahr, M. D., Duvoisin, R. C., Schear, M. J., Barrett, R. E., and Hoehn, M. M. (1969). Treatment of parkinsonism with levodopa. Archives of Neurology, 21, 343-354.

Yahr, M. D. (1970). Treatment failures with L-dopa. In L-dopa and Parkinsonism. pp. 5-8. Edited by A. Barbeau and F. H. McDowell. Davis: Philadelphia. 